\title{
Development of a three-tier system of parameters in the formation of the organizational and technological potential of using non-destructive testing methods
}

\author{
Azariy Lapidus, Alan Khubaev ${ }^{*}$ and Tembot Bidov \\ Moscow State University of Civil Engineering, Yaroslavskoe shosse, 26, Moscow, 129337, Russia
}

\begin{abstract}
The efficiency potential of organizational and technological solutions using the methods of non-destructive testing of the strength of monolithic structures in the construction of civil buildings and structures has been investigated. In this article scientific and technical hypothesis was compiled. It consists in the assumption of the possibility of developing a system for evaluating the organizational-technological potential of using non-destructive testing methods based on the method of qualimetric analysis. The four most significant groups of parameters were identified on the basis of this method. They can have a significant impact on the organizational and technological potential of using non-destructive testing methods. The orthogonal central compositional plan was chosen as the basis for planning the experiment. This will reduce the number of experiments in the formation of the potential to 25 , and to assess the degree of influence of each production and technological module in the implementation of the construction project. The system of variation of groups of parameters consisting of three levels was formed for the purpose of further research based on the tree of goals. The basis for the mathematical apparatus is prepared. This unit characterizes the parameters of the object.
\end{abstract}

\section{Introduction}

Scientific and technical progress in the field of concrete production technology is inextricably linked with the introduction of non-destructive quality control methods into building practice. Non-destructive methods of quality control of concrete is the definition of the strength characteristics of the structure without its destruction using devices and methods corresponding to them. [1]

*Corresponding author: alan_khubaev@mail.ru 


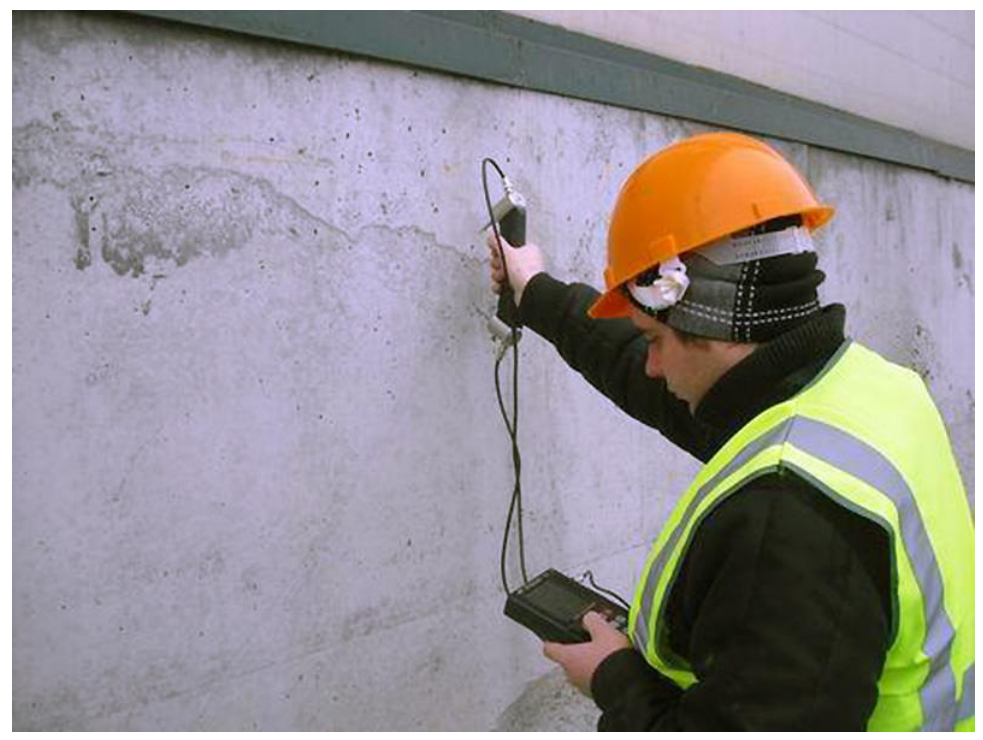

Fig. 1. Concrete testing process

The mechanism of organizational and technological operational actions has a decisive role in making decisions about the use of non-destructive testing devices and the choice of their control method. The tool, allowing to assess the validity of the use of non-destructive testing methods in the construction of monolithic reinforced concrete structures of civil buildings and structures is missing today. Such a tool can be developed with the help of organizational and technological solutions and the formation of the parameter $\mathrm{P}_{\text {n.c. }}$ "The organizational and technological potential of using non-destructive testing methods in the construction of monolithic structures of civil buildings". This concept is a comprehensive indicator of the effectiveness of organizational, technological and managerial measures when it is determined at the very beginning of a construction project. And it allows you to give an intermediate assessment of the effectiveness when considering the completed project. [2]

A lot of research is being done on the study of "potential" in the scientific literature today. They describe the level of effectiveness of the adopted organizational, technological and managerial decisions in the implementation of the construction project. [3, 4, 6-11].

Production and technology modules were described in detail when studying the organizational and technological potential of using non-destructive testing methods today. They characterize the seasonal conditions of inspection, and in more detail, the influence of the potential in the production of concrete work during the winter period and the application of non-destructive testing methods. [13-16, 19, 20]. Other factors have been investigated too. Next, they were subjected to statistical processing by the method of qualimetric analysis. This allowed us to form the final list of factors: $[5,17,18]$

- Readiness of the construction site for testing (X1);

- Availability and timeliness of concrete information (X2);

- Staff qualification (X3);

- Project documentation quality (X4);

- Application of the non-destructive control methods (direct, indirect);

- Seasonal check conditions (X6);

- Presence of the laboratory at the construction site (X7). 
The need to optimize all the above-described production and technology modules and get the group optimization is the next step. It was necessary to create optimal conditions. They are needed to find the studied organizational and technological potential of using nondestructive testing methods.

Four groups of interrelated variables were formed after analyzing correlations. This was enough for the experiment:

- Z1 group z1 characterizes the readiness of the construction site for testing and the use of non-destructive testing (direct, indirect);

- Z2 group describes the availability of information about concrete and the presence of laboratories at a construction site;

- Z3 group describes the sophistication of organizational and technological documentation and the level of staff qualifications;

- Z4 group reflects seasonal verification conditions.

\section{Material and Methods}

Domestic and foreign research methods are available in sufficient quantities today. They can be used to study the quality of the adopted organizational and technological solutions using non-destructive testing methods. The following methods were used to solve the tasks:

- Qualimetric analysis.

- Systems engineering in construction,

- Information technology

- Organizational and technological reliability.

- Develop an experiment plan.

The next step was to determine the nature of the dependence of non-destructive testing potential on organizational and technological solutions. This mean an experiment.

A sufficient number of experiments must be determined to solve the problems with the required accuracy. This process is necessary for conducting an experiment in a study. We will use the theory of experiment planning to perform this task. This will minimize the time and cost of the experiments, as well as modernize the mathematical model without losing the available information if necessary.

The experiment planning method solves extremely diverse problems. These are tasks such as: finding optimal conditions; the construction of interpolation formulas, the choice of significant factors; evaluation and refinement of the constants of theoretical models; the choice of the most acceptable of some set of hypotheses about the mechanism of the phenomenon.

The stages of planning an experiment are described by the following sequence in research:

1. Setting the goal of the experiment.

2. Refinement of the conditions of the experiment.

3. Identification and selection of input and output parameters.

4. Establishing the required accuracy of measurement results.

5. Making a plan and conducting an experiment.

6. Statistical processing of experimental results.

7. Construction of a mathematical model.

8. Explanation of the results

The response function ( $\mathrm{Y}$ ) has a correlation dependence on the influencing factors ( $\mathrm{Zi})$, if we take into account the fact that the desired model is statistical, and the processes under study are probabilistic in nature. And we can get different values of the output parameter for a fixed value of the factor. Finding a mathematical model in the form of a regression 
equation will therefore be the goal of this multifactor experiment. She can adequately describe the results of the experiment.

We do not know in advance the analytical expression of the response function. Therefore, we will consider the function itself as a second degree polynomial:

$$
y_{i}=b_{0}+\sum_{i=1}^{k} b_{i} \times z_{1}+\sum_{i, i=1}^{k} b_{i i} \times z_{i i}^{2}+\sum_{i, j=1}^{k} b_{i j} \times z_{i} \times z_{j}
$$

Where, «y» - the calculated value of the output parameter, «b» - the coefficients of the regression equation, «Z»-the coded values of the factors.

We must set the levels of variation of the factors to get the coded values of the factors after they are selected. The level of variation means the totality of values that a factor may take in the course of studying its influence The center point is assumed to be the main level. It is called the zero point and is denoted by Z0. The variation interval is called $\Delta \mathrm{z}$. This formula determines the relationship between natural $(\mathrm{z})$ and coded values $(\mathrm{Z})$ factors:

$$
Z_{i}=\frac{z_{i}-z_{0}}{\Delta z}
$$

The factors studied should be quantified. This is necessary for planning an experiment. The experiment can be planned by quality indicators, if such as we do not have the opportunity. Then we must develop a scale for evaluating factors in conditional points in advance.

\section{Results}

When we carried out the preparation for the experiment, it was necessary to rank the groups of factors by qualitative indicators based on the tree of objectives (Fig. 1). A complex property is located at the top of this tree (organizational and technological potential of using non-destructive testing methods). The middle level is represented by formed groups of parameters. They have their own characteristics, which are presented in conditional points from $«-1 »$ to $«+1 »$.

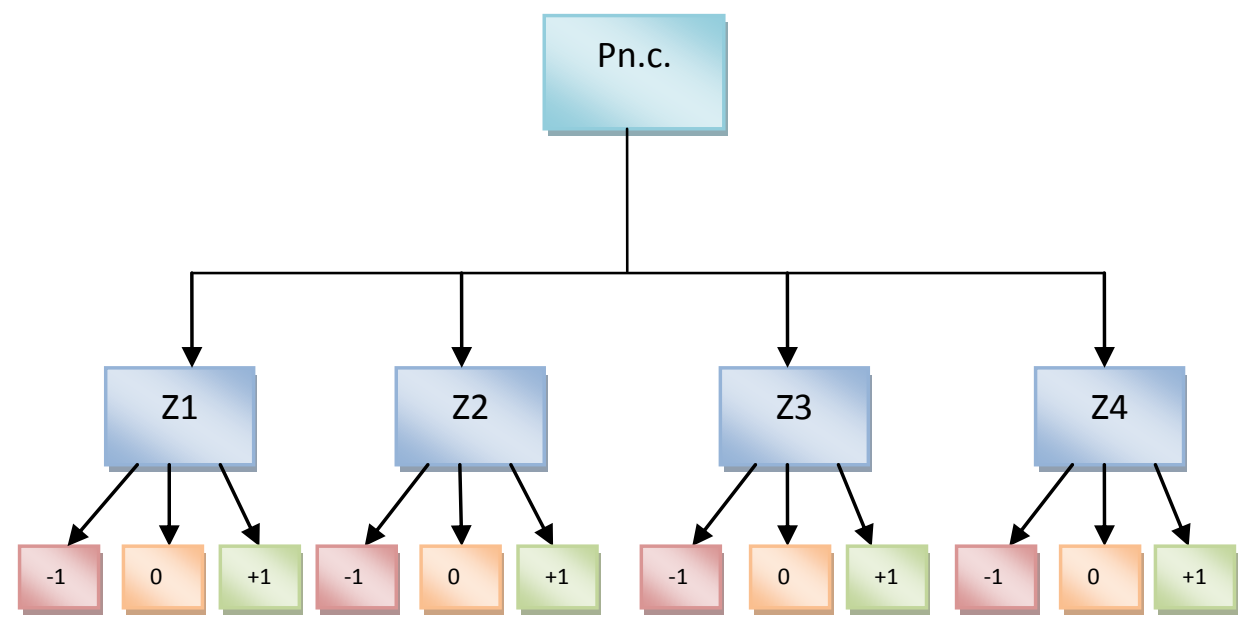

Fig. 2. The tree of objectives 
We have formed the following levels for the group z1. They look like this:

«-1» - The site is not ready for testing, there are defects in the measurement area, the surface layer is damaged, the test site has not been cleared. Only the indirect method is applied (the staff used only 1 devices from the mechanical or ultrasonic groups);

$\langle 0 »-$ Responsible personnel are aware of the arrival of specialists, there are no defects in the measurement area, the test site is not illuminated, there are hard-to-access places for control. The staff used the direct method of non-destructive testing with respect to regulatory requirements;

« $+1 »-$ The construction site is fully prepared for testing, all places have been cleaned and prepared for testing, there are no hard-to-reach places to control the strength of structures. The staff uses the direct method of non-destructive testing (separation with chipping, rib chipping) + indirect using devices from groups (mechanical, ultrasonic).

For group z2:

«-1»- Information about the tested structures at the time of testing is not available. The journal of concrete work is conducted incorrectly. The laboratory goes to the site after the call;

«0»- Information about the tested structures are not given in full. The log of concrete work is conducted incorrectly. Passports and certificates are transmitted late. The laboratory goes to the construction site in accordance with the previously agreed schedule of work;

$«+1 »$ - Information about the tested structures are given in full. The magazine of concrete work is completed in a timely and correct manner. Concreting schemes are attached. Laboratories are constantly present at the facility under construction.

For the group z3:

«-1» - We have only working documentation at the time of the start of testing. The representative of the laboratory does not have a full higher education. The representative of the laboratory has no experience.

$\langle 0 »-$ We have only a standard project for the production of works agreed with the customer. He has no information about the control of the strength of concrete. The representative of the laboratory has a higher education. Representative laboratory experience from 1 to 3 years.

«-1»- All organizational and technological documentation is on the construction site is available. Documentation describes in detail the process of testing non-destructive methods. The representative of the laboratory has a higher education. The representative of the laboratory has experience of more than 3 years.

For group z4:

«-1»- Winter period;

$« 0 »-$ Autumn-spring period;

$«+1 »-$ Summer period.

\section{Conclusion}

We identified four groups of factors as a result of factor analysis and analysis of variance. These groups of factors have the greatest impact on the organizational and technological potential of using non-destructive testing methods. Three levels of variation have been proposed for each group.

We can create optimal conditions for future experiments due to the work done. These results are the basis for creating a mathematical tool. It will allow you to quite fully characterize the possibilities of a construction object.

This work was financially supported by Ministry of Science and Higher Education of the Russian Federation (\#NSh-3492.2018.8). 


\section{References}

1. A. Goncharov, T. Bidov, G. Treskina, Scientific review, 12, 68-72 (2015)

2. A. Lapidus, Vestnik MGSU, 1, 175-180 (2014)

3. Lapidus A.A., Govorukha P.A., International Journal of Applied Engineering Research, Vol. 10. № 20. p.40946-40949 (2015)

4. Govorukha P., Scientific review, 13, 11-16 (2017)

5. A. Lapidus, T. Bidov, International Journal of Applied Engineering Research, Volume 11, 8, 5972-5974 (2016).

6. R. Fatullaev, Components of Scientific and Technological Progress, 3 (33), 17-22 (2017)

7. Feldman A., Science and business: Development ways, 12(78), 24-27 (2017)

8. Govorukha P., Science and business: Development ways, 3(81), 85-88 (2018)

9. R. Fatullaev, Science and business: Development ways, 9(75), 34-40 (2017)

10. D.Topchiy, Technology and organization of construction production, 3(8), 40-42.(2014)

11. A. Lapidus, A. Makarov, Bulletin of Moscow State University of Civil Engineering, 8, 150-160 (2015)

12. D.Topchiy, Technology and organization of construction production, 4, 34-41.(2014)

13. A. Lapidus, A. Khubaev, Science and business: Development ways, 11(77), 7-11 (2017)

14. Khubaev, Science prospects, 4 (103), 57-61 (2018)

15. T. Bidov, Scientific review, 13, pp. 54-57 (2017)

16. A. Khubaev, T. Bidov, Science and business: Development ways, 4(82), 101-103 (2018)

17. A. Lapidus, T. Bidov, A. Khubaev, MATEC web of conferences, V. No. 00094, (DOI: 13.1051/matecconf/201711700094 (2017)

18. A. Lapidus, A. Khubaev and T. Bidov., MATEC Web of Conference, V. № 05014, DOI: 17.1051/matecconf/201825105014 (2018)

19. A. Lapidus, I. Abramov, Science and Business: Development ways, 10 (2017)

20. A.Lapidus, K. Tolstova, Industrial and civil engineering, 5, 68-71 (2016) 